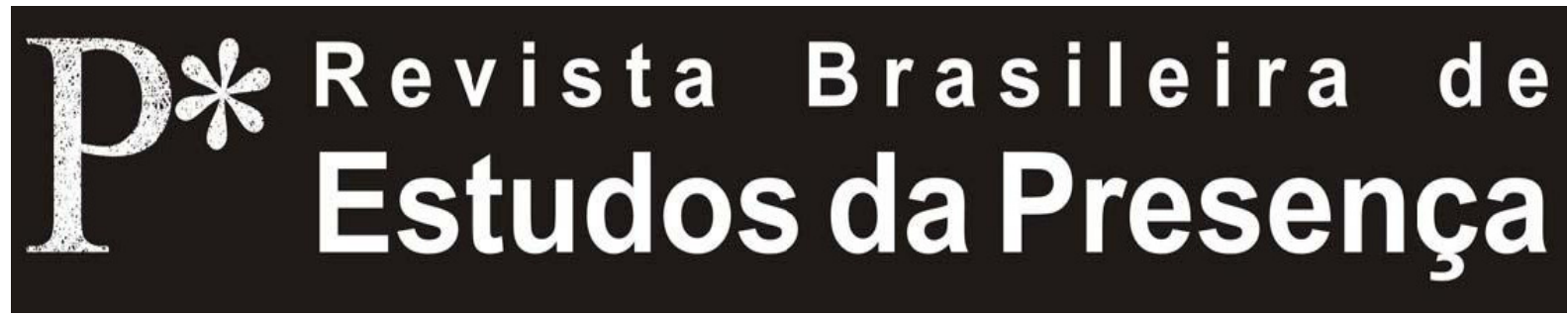

DOI - http://dx.doi.org/10.1590/2237-266030163

ISSN 2237-2660

\title{
Presença ou a Qualidade Discreta do Estar Ali
}

\author{
Maíra Castilhos Coelho \\ Universidade Federal do Rio Grande do Sul - UFRGS, Porto Alegre/RS, Brasil
}

RESUMO - Presença ou a Qualidade Discreta do Estar Ali - Este texto parte de algumas noçóes de presença do ator, objetivando versar sobre essa qualidade do estar e o efeito de presença. Discute-se o estatuto da presença no teatro, entre atores e espectadores, no presente e ao vivo, e questiona-se o fato de que nem sempre há na cena um ator com presença. Este texto trata a presença como qualidade do ator, não como algo constante ou alguma coisa que aprendemos e reproduzimos. Passeia-se, assim, por noçóes como corpo extracotidiano, corpo dilatado, ação interior, estar no presente, entre outras.

Palavras-chave: Ator. Presença. Teatro. Ausência. Efeito de Presença.

ABSTRACT - Presence or the Quality of Discreetly Being There - This text is based on some notions of the actor presence, aiming to discuss this quality of being and the effect of presence. It discusses the status of presence in theatre, between actors and spectators, in the here an now, live, and questions the fact that not all actors on a stage have presence. This paper addresses presence as a quality of the actor, not as constant or as something we learn and reproduce. Thus, we discuss different notions like extra-daily body, dilated body, inner action, being in the present, among others.

Keywords: Actor. Presence. Theatre. Absence. Presence Effect.

RÉSUMÉ - La Présence ou la Qualité Discrète d'Être Là - Ce texte s'appuie sur quelques notions de présence de l'acteur pour envisager cette qualité particulière d'être là ainsi que l'effet de présence. Il propose une réflexion sur le statut de la présence sur scène, parmi les acteurs et spectateurs, au présent et en direct. Considérant qu'il n'existe pas toujours d'acteur avec présence sur scène, celle-ci serait alors un état que l'acteur arrive parfois à atteindre, au-delà de sa simple présence physique. Des notions telles que corps extra-quotidien, corps dilaté, action intérieure, être au présent, entre autres, y sont également abordées.

Mots-clés: Acteur. Présence. Théâtre. Absence. Effet de Présence. 
A presença não é algo constante ou alguma coisa que aprendemos e reproduzimos. Mas como perceber e analisar a presença? Pela simples presença física? Por uma sensaçáo de presença? O que significa este estar presente? Segundo Josette Féral ${ }^{1}$, a presença pode ser analisada em termos de presença corporal, sensação ou estado mental.

A presença corporal seria de natureza existencial, ou seja, ela trabalha com a ideia de que, simplesmente, a pessoa está ali. Evidentemente, é um conceito muito amplo. Já a sensação aconteceria através do espectador, aquele que percebe, que recebe a presença. E, por fim, o estado mental remete à ideia da pessoa estar ali fisicamente, mas não mentalmente. Quando se está num lugar, num espetáculo e se tem a sensação de estar ausente. Essa ideia de estado mental é muito importante, porque a pessoa pode estar ali fisicamente, mas não mentalmente.

Além disso, dizer que um ator está presente ou tem presença remete à ideia da qualidade do estar ali. Ou seja, a maneira de estar presente é a que afirma náo apenas o estar presente fisicamente, mas a forma de estar presente para se ter presença - o que não quer dizer a mesma coisa.

Dessa forma, quando diretores dizem aos seus atores para estar no presente, este estar presente, no presente, para os atores já é um estado além do estar normalmente. Assim, passamos do sentido inicial do verbo ser para o estar presente. Portanto, estar presente tem o sentido de ter presença. Segundo J. Féral ${ }^{2}$, esta passagem da locução sintática do estar presente para o substantivo presença já é uma mudança de natureza. Nessa perspectiva, há uma diferença entre o afirmativo do eu estou aqui e o qualitativo, que é a modalidade desse estar ali. Assim, tais definiçóes se apresentam no sentido de avaliar o estar, de avaliar as qualidades da presença.

Segundo Silva (2010, p. 34), a presença se encontra relacionada ao grau de alteridade conquistada pelo ator ao olhar da recepçáo. Portanto, para falar de presença é necessário pensar no impacto que esta produz no público.

Para Dusigne (2001, p. 21), a época, o contexto, a percepção influenciam nos critérios de apreciação do espectador. Diz ainda que Marcel Proust, em seu esboço para À Sombra das Moças em Flor, transcreve de maneira muito eloquente a fascinação que Sarah Bernhardt causava antes mesmo de entrar em cena. 
A explosão de seu nome sobre as colunas Morris, a evocação de sua beleza "uma beleza eloquente", a perfeição da "atuação de Sarah Bernhardt em Fedra" desperta nele, um desejo táo mais poderoso e obsessivo, que os comentários ou os superlativos que a descrevem se tornam vagos. Bem, uma vez no teatro, a visão constantemente brilhante da atriz em cena, a palavra que escapa, o desejo que isso não acabe nunca, provocam nele uma imensa decepção. Enquanto ele se convence de que é sublime ele segue "bem constrangido de saber porque", uma mulher exclama: "Ela não guarda sua pena, ela diz a verdade, ela se bate, ela grita, fale-me disso, isso é atuar" (Dusigne, 2001, p. 23) ${ }^{3}$.

Dessa forma, a noçáo de presença se torna flutuante e ideológica. Para Dullin (apud Dusigne, 2001, p. 22): “[...] é precisamente esta qualidade discreta que emana da alma, que irradia... e que se impóe é esta famosa presença que distingue o modelo do ator".

Já Stanislavski (apud Dusigne, 2001, p. 26) parte da constatação que "[...] o estado de espírito do ator que se mantém diante de uma plataforma deslumbrante e de milhares de espectadores é um estado contra natureza, que representa o obstáculo principal para a criaçáo pública" . Além disso, estimulado por Tchekhov, passou a valorizar o silêncio entre as palavras, apreciando, assim, as pausas, os olhares dos atores e o brilho de suas emoçóes profundas que colocavam em evidência o quanto a presença do ator em cena poderia estar repleta de significado.

Para Ariane Mnouchkine, a presença é alguma coisa que se constata. Dessa forma, procura fazer com que o ator esteja no presente em sua ação, em sua emoção.

São as lições que nos dá Shakespeare. Sentimos junto com ele que se pode começar um verso numa cólera assassina e ter um instante de esquecimento dessa cólera, para sentir-se apenas alegre com alguma coisa que está no texto, para, em seguida, recair num atroz desejo de vingança e tudo isso em dois versos, quer dizer, em alguns segundos. Então, o presente está hiperpresente. Está presente naquele segundo. Quanto ao próprio conceito de presença do ator, aí... há atores que são presentes e outros menos. Um bom ator está presente. Isso tem a ver com o dom. Náo há mau ator que tenha presença ou, então, trata-se de uma má presença. A presença progride com a capacidade de desnudar-se de um ator (Mnouchkine apud Féral, 2010, p. 75-76).

Além disso, a diretora (apud Dusigne, 2001, p. 27) considera que, para trabalhar um ator, este precisa produzir, desde o primeiro passo em cena, um "som mínimo". Nos ensaios do Théâtre du Soleil, 
Jean-Jacques Lemêtre apenas começa a improvisar sobre a atuação dos atores a partir do momento em que ele percebe neles uma música interior, que se manifesta por um ritmo particular, diferente do simples comportamento cotidiano ou familiar.

Para ela, a narrativa acontece no palco na instantaneidade do momento, diante do espectador, em colaboraçáo com os outros atores. "Para isso, é preciso que se concentre não no que vai acontecer no palco ou no que aconteceu, mas no que acontece naquele instante. Mnouchkine exige que o ator esteja inteiramente, absolutamente, no presente" (apud Féral, 2010, p. 45). O ator deve poder aliar sua concentração à imaginaçáo e fazer ato de fé. Acreditar verdadeiramente no que ele imagina, se tornar realmente presente ao que é proposto. E é a partir disso que vem, em parte, a presença. Desta forma, para estar presente o ator deve saber inscrever-se nessa instantaneidade.

Para Grotowski, o fundamental estaria na relação estabelecida entre $\mathrm{o}$ ator e a plateia, não nos cenários e nos figurinos ou na iluminação. E esta é, de certa forma, a busca do "Teatro Pobre", que desejava estabelecer uma relaçáo direta com os espectadores no terreno da pura percepção e da comunhão. Pretendia reevocar uma forma muito antiga de arte, onde o ritual e a criação artística estivessem perfeitamente integrados. "A especificidade do teatro é o contato vivo e imediato entre ator e espectador; é necessário encontrar uma estrutura espacial unificadora para atores e espectadores sem a qual o contato fica jogado ao acaso; o espetáculo é a centelha que nasce do contato entre dois conjuntos: o dos atores e o dos espectadores [...]" (Barba, 1994, p. 200). Nesse ato de comunháo o papel do ator se torna fundamental e, para isso, seria necessário haver presença.

A Antropologia Teatral se define como o estudo do comportamento pré-expressivo do ser humano em situação de representação organizada. E esse nível pré-expressivo exige um treinamento diário do ator. Para Eugenio Barba (1994, p. 23):

Trata-se de uma qualidade extracotidiana da energia que torna o corpo teatralmente "decidido", "vivo", "crível"; desse modo a presença do ator, seu bios cênico, consegue manter a atenção do espectador antes de transmitir qualquer mensagem. [...] A base pré-expressiva constitui o nível de organização elementar do teatro.

Assim, a presença física e mental do ator modela-se segundo princípios diferentes dos da vida cotidiana. A utilização extracotidiana do corpo-mente é aquilo a que se chama "técnica". E as diferentes 
técnicas do ator podem ser conscientes e codificadas; ou náo-conscientes, mas implícitas nos afazeres e na repetição da prática teatral.

Como utilizamos nosso corpo de maneira diferente na vida cotidiana e nas situaçóes de representaçáo, podemos então distinguir uma técnica cotidiana de uma técnica extracotidiana. Diariamente, usamos uma técnica corporal condicionada por nossa cultura e nossa condição social. Já numa representação, há uma utilização do corpo totalmente diferente.

Segundo Barba (2009, p. 34), as técnicas cotidianas do corpo são, em geral, caracterizadas pelo princípio do esforço mínimo, ou seja, alcançar o rendimento máximo com o mínimo uso de energia. As técnicas extracotidianas baseiam-se, pelo contrário, no esbanjamento de energia. Em alguns casos, até parecem sugerir um princípio oposto em relação ao que caracteriza as técnicas cotidianas, o princípio do uso máximo de energia para um resultado mínimo.

Dessa forma, segundo De Marinis (1997, p. 89-90)7 , as investigaçóes de Barba sobre a antropologia teatral apontam para a existência de uma "zona intermédia" entre a vida cotidiana e a representação, entre o ator e o personagem.

A essa zona pertenceria uma série de regras que não são nem "atorais" nem expressivas e que poderíamos chamar também de técnicas da presença dramática: trata-se daquelas técnicas que, como escreve Barba, caracterizam "a vida do ator [...] inclusive antes que esta vida comece a representar algo ou a expressar-se".

Além disso, Pina Bausch reafirmava o quanto seria importante para o bailarino saber dançar sentado, aparentemente imóvel numa cadeira. Segundo Barba (2009, p. 90), em seus espetáculos ela "imobilizou" muitas vezes a dança dos seus atores.

Quando o que é visível, o exterior (o corpo), não se move, é necessário que o interior (a mente) esteja em movimento. O modelo é o cisne sobre a água: desliza impassível, mas as patas, escondidas, trabalham sem descanso. No movimento, imóvel; na quietude, inquieto. "A estaticidade é um movimento a tal nível, que não transporta o corpo do espectador, mas simplesmente a sua mente". Assim Matisse explicava o efeito cinestésico das cores sobre telas planas.

Portanto, cada movimento deve surgir da imobilidade. Para Grotowski, este antemovimento pode ser realizado em diferentes níveis, como uma espécie de silêncio antes do movimento - porém, um silêncio cheio de potencial. Etienne Decroux (apud Barba, 2009, 
p. 94) também fala dessa imobilidade em movimento, que estaria presente na pressão das águas sobre o dique, na mosca detida pelo vidro, forçada a voar no mesmo lugar, no desmoronamento adiado da torre que se inclina, mas se mantém ereta.

Segundo Farcy (2001, p. 15), Peter Brook prefere falar de "brilho essencial" 8 mais do que de presença. E refere-se ainda a uma famosa expressão utilizada para designar a presença: "je ne sais quoi" .

Patrice Pavis (2010, p. 176) fala que, além da concepçáo idealista de presença, é possível existir outras formas de presença devido ao uso das novas tecnologias. $\mathrm{Na}$ encenaçáo contemporânea, muitos espetáculos utilizam a internet como forma de comunicação, onde o ator, embora não esteja presente no palco, aparece conectado diretamente. Para o autor, nesta concorrência entre a imagem fílmica e o corpo "real" do ator, o espectador náo escolhe necessariamente o vivo contra o inanimado. O seu olho é atraído por aquilo que é visível em maior escala, visto que não cessa de evoluir e retém a atenção pela mudança constante de planos e escalas.

$\mathrm{E}$, neste teatro, chamado de cibernético (Cyber Theatre) por Pavis, o uso de novas mídias e tecnologias da informática possibilitam a criaçáo de espaços virtuais, onde a presença não está mais, necessariamente, ligada ao corpo visível do ator.

$\mathrm{O}$ ator pode, assim, muito bem estar ausente do espaço cênico, e estar absolutamente presente num lugar totalmente distinto. A presença não está mais ligada ao corpo visível. $\mathrm{Se}$ estou ao telefone, estou presente-livre, mas evidentemente ausente no espaço visível (inversamente ousaríamos dizer, se estou perdido nos meus pensamentos, meu corpo está lá, porém eu não estou lá, meu espírito está alhures, ausente para alguém que queira falar comigo) (Pavis, 2010, p. 176).

Dessa forma, se podemos estar ausentes, embora estejamos fisicamente presentes num palco, talvez seja possível haver algum tipo de presença num ator ausente (virtual). Portanto, a ideia de ausência é fundamental e nos faz pensar na ideia de presença. E essa ideia se confirma quando se constata que, pela tela da câmera, tal pessoa está presente ou parece estar fortemente presente. A imagem consegue produzir uma ideia de presença, como se ela estivesse ali, e essa reflexão pressupóe também uma constatação da ideia de ausência.

$\mathrm{O}$ fato é que a noção de presença está baseada num paradoxo entre presença e ausência. Assim sendo, a ideia de ausência é fundamental e nos faz pensar na presença. Para Marleau: 
O que me interessa, em definitivo, é ver como um ator chega a se ausentar na apresentação. Para ser explícito, eu penso que não podemos interrogar e investir esta noção de presença no teatro sem se opor ao seu contrário: a ausência. Porque entre estes dois polos, todas as espécies de graus de presença acontecem na apresentaçáo, diante de si mesmo ou dos outros, ou dos dois por sua vez. Existe toda uma gama de estados de presença que o intérprete deve poder explorar nos textos de Samuel Beckett ou de Jon Fosse. Existem as zonas intermediárias de onde falam seus personagens que fazem ouvir muitos fantasmas em suas vozes cheias de lembranças, de sonhos, de lapsos e de inquietudes. Isso nos remete ainda à Tadeusz Kantor que usava a marionete ou a boneca de cera como modelo vivo para o ator (apud Proust, 2010, p. $64-65)^{10}$.

\section{O Efeito de Presença}

Conforme já viemos discutindo, a definição da noção de presença é vaga, intangível e impalpável, principalmente por não poder ser simplesmente religada à dimensão física, ao corpo do ator. A presença, sobretudo, é apoiada pelo corpo, mas não coincide com ele. Poderíamos dizer que a presença é uma espécie de capacidade do ator de se manifestar no espaço em suas trajetórias.

Além disso, a internet e as imagens em vídeo criam a ilusão e a impressão de que as pessoas realmente estão ali presentes - de tal maneira que essa presença na tela nos provoca reaçóes muito semelhantes das que temos quando estamos de fato diante de uma pessoa presente. Essa sensação de haver uma presença que não é real seria o que Féral ${ }^{11}$ chama de "efeito de presença". Vale ressaltar que ambos os conceitos, o de presença e o do efeito de presença, náo são a mesma coisa, mas são interligados.

Pensei no filme 'A rosa púrpura do Cairo', em que ele sai da tela. E me veio a minha relação com o cinema, e talvez as pessoas tenham isso com TV também, eu acho que tem alguma coisa, mas eu nunca parei pra pensar nisso tấo concretamente, porque a gente tem a impressão que a gente conhece alguns atores pela experiência do filme, que o corpo não está presente? E eu nem estou falando de filmes que tentam reproduzir esta vida, este contato, que olha pra mim, ou tem a ver com a minha vida, eu estou falando de experiências diversas, onde a gente tem essa experiência da pele, intermediada, e você tem a sensação que conhece aquela figura, e é muito louco isso, você conhece a pessoa do ator, tem uma textura, pra mim ela ultrapassa, mas eu não sei, presença tem a ver com o contato real, ao mesmo tempo a gente é intermediário de muita coisa (entrevista com Juliana Jardim, concedida em 2010, comunicação verbal). 
E quando se fala sobre o efeito de presença é importante pensar na ideia de grau de presença e de presença do ator. A diferença é que o conceito de efeito de presença remete à ideia de sensaçáo de presença, como a palavra propriamente diz - um efeito de presença, e não a presença em si. Assim, o efeito de presença nasce de experiências que dão a impressão de que há mesmo alguém ali, embora não haja ninguém.

E, segundo Féral ${ }^{12}$, numa situação em que não há ninguém, apesar da pessoa ter a impressão de que há alguém e saber racionalmente que não há outro no ambiente, ela tem a sensação de que há alguém ali, e assim vive o efeito de presença. E é neste faz de conta, neste como se, que surge o jogo de ilusão que cria esta outra presença.

Isso acontece, por exemplo, nas instalaçóes de Janet Cardiff ${ }^{13} \mathrm{e}$ de outros artistas, que utilizam recursos tecnológicos ou digitais para criar esse efeito de presença. Nesses casos, a impressáo de presença aparece da experiência da pessoa que vive as mesmas sensaçóes e percepçóes de quando se está na presença real de alguém.

O efeito de presença é um sentimento, uma sensação, que o espectador tem de que os corpos ou os objetos que estão oferecidos ao seu olhar ou a sua escuta estão realmente ali. No mesmo espaço e no mesmo tempo dos quais eles se encontram (entrevista com Josete Féral, concedida em 2010, comunicação verbal).

Assim, o efeito de presença é um sentimento, uma sensação, que o espectador tem de que os corpos ou os objetos que estão oferecidos ao seu olhar ou a sua escuta estáo realmente ali, no mesmo espaço e no mesmo tempo nos quais ele se encontra.

Outro exemplo de efeito de presente acontece no espetáculo "Os Cegos"14, de Maurice Maeterlinck, encenado por Denis Marleau, no Museu de Arte Contemporânea de Montréal, em 2002.

A peça também foi chamada de fantasmagoria tecnológica, pois uma de suas particularidades é, justamente, o fato de que os atores, ainda que visíveis ao público, estáo ausentes. Para encenar o texto, Denis Marleau colocou doze faces humanas espalhadas em um espaço escuro, indeterminado. As faces dos atores são projetadas em máscaras que se encontram fixadas no espaço cênico, gerando o efeito de presença do ator. Tamanha é a semelhança com o real, que o espectador chega a acreditar que o ator está presente fisicamente na cena. 
Elas representam alguma referência, como todo o signo, mas elas o apresentam também, elas lhe dão uma presença real, uma espécie de transubstanciação. Mas esta presença segue singular. Ela não é mais aquela, utópica, da representação clássica, onde o signo desaparece para melhor representar sua referência, nem ainda aquela, também utópica, da representação moderna, onde a referência se apresenta ela mesma fora de todo signo. Ela é uma presença marcada pela ausência, uma ausência estranhamente presente, uma nova aura - "a única aparição distante, por mais próxima que seja”, como a definia Benjamin (Asselin, 2002, p. 26) ${ }^{15}$.

Além disso, citando Jean-Louis Weissberg (2000), Féral ${ }^{16}$ ressalta que o efeito de presença não é um estado contínuo, mas sim um sentimento de presença que aparece e desaparece numa sucessáo, gerando, a partir dessa alternância de momentos de presença e de ausência, uma sensação, um sentimento de um estado de presença.

Portanto, esta ideia de presença não-corporal, possível graças à utilização das novas tecnologias, cria no espaço a impressão de um corpo estranho sem presença real. Todos os ingredientes da presença estão ali e, no entanto, não há corpo ao vivo. Segundo Silva (2010, p. 35), essa estranheza está dialeticamente relacionada com essa sensação de presença vivida pelo espectador:

Mais precisamente, o sentido de presença percebido pelo espectador aparece como instaurado em um "entre" das realidades diversas, fruto náo do contato com uma imagem, mas como uma experiência global da cena.

Cabe ainda ressaltar que, com o avanço das novas imagens nos anos 1980 e depois da virtualidade, surgiram novas transformaçóes no domínio da criação, da difusão e da realização dos espetáculos, propiciando questionamentos em relaçáo à definição da cena e da tela, do ator e do espectador.

Diante de uma cultura das imagens, as técnicas virtuais colocam em questáo a definiçáo dos diferentes elementos e parceiros que compóem a essência de uma representaçáo teatral. As novas tecnologias conduzem uma ligaçáo que funde o espectador e a imagem, transformando o sentido de ver, materializando sons e oferecendo o invisível a olho nu.

A encenação da imagem cinematográfica, da montagem televisiva ou da velocidade dos links na Internet, ilumina um olhar e um comportamento cada vez mais midiatizado e essencialmente estético. Os níveis de interfaces variam nos corpos plugados e vão do patamar 
mais superficial ao mais imersivo. Tudo o que ocupa um lugar na cena se reveste com seu manto de ilusão, jogo e encenação.

$\mathrm{E}$, numa época onde os ciborgues se movem no ciberespaço enquanto seus corpos ficam plugados no computador, com as possibilidades da telepresença, com as técnicas de motion capture dos atores, que permitem fazer nascer as marionetes, com o desenvolvimento do virtual, Picon-Vallin ressalva sobre as novas potencialidades e novos perigos.

Porque, se o princípio estrutural do teatro é exatamente a relação múltipla, a troca entre os seres humanos reunidos, assim como a tecnologia das imagens simples ou sofisticadas permite transformar, modificar essa relação, essa intersecção, sem a anestesiar, mas a tornando mais consciente e/ ou mais sensível, toca o coração do teatro e, por isso, deve ser interrogada, como deve ser também o desinteresse obstinado do número de artistas de teatro para as novidades (Picon-Vallin, 1998, p. 9-10) ${ }^{17}$.

Assim, as telas permitem abrir a cena para novos espaços, podem transformar a percepção do público, permitir a exploração de um mundo em transformação, e possibilitar a imaginação.

$\mathrm{E} o$ ator virtual que surge na cena, tấo ausente quanto presente, dá origem a um espetáculo sem o convívio tradicional, mas com uma nova forma de convívio. Isso porque existe a crença de que há alguém no palco - através do efeito de presença, aflora a sensaçáo de convívio, ocorre o crédito nesta presença.

O fato é que este teatro cibernético nos leva a pensar que talvez estejamos em meio a um processo de redefinição dos limites do teatro. Estamos diante da necessidade de repensar os princípios estéticos do teatro contemporâneo frente às novas tecnologias, uma vez que elas possibilitam deslocarmos o aqui e agora e o surgimento de uma nova forma de presença. 


\section{Notas}

${ }^{1}$ Em palestra proferida no III Seminário Internacional sobre Teatro, Dança e Performance, com o tema Poéticas Tecnológicas, de Salvador, em 05 de novembro de 2010.

${ }^{2}$ Idem.

${ }^{3}$ Le flamboiement de son nom sur les colonnes Morris, l'évocation de sa beauté, "une beauté de diction", la perfection du "jeu de Sarah Bernhardt dans Phèdre" attise en lui, un désir d'autant plus puissant et obsessionnel, que les commentaires ou les superlatifs qui la décrivent sont vagues. Or une fois au théâtre, la vision sans cesse fuyante de l'actrice en scène, la parole qui échappe, le vouloir que cela ne finisse jamais, provoquent en lui une immense déception. Tandis qu'il se convainc lui-même que c'est sublime tout en étant "bien embarrassé de savoir pourquoi", une dame s'exclame: "Elle n'épargne pas sa peine, elle court pour de vrai, elle se frappe, elle crie, parlez-moi de ça, c'est jouer" (Tradução Helena Mello).

${ }^{4}$ C'est précisément cette "qualité discrète qui émane de l'âme, qui irradie... et qui impose", c'est cette fameuse présence qui distingue le mannequin du comédien (Tradução Helena Mello).

${ }^{5}$ L'état d'esprit de l'acteur qui se tient devant une rampe éblouissante et des milliers de spectateurs est un état contre nature, qui représente l'obstacle principal à la création publique (Tradução Helena Mello).

${ }^{6}$ Ariane Mnouchkine Parle quant à elle de "son minimum” (Tradução Helena Mello).

${ }^{7}$ A esa zona pertenecería una serie de reglas que no son ni actorales ni expresivas y que podríamos llamar también técnicas de la presencia dramática: se trata de aquellas técnicas que, como escribe Barba, caracterizan "la vida del actor [...] incluso antes de que esta vida comience a representar algo o a expresarse" (Tradução Clair Castilhos).

8 “rayonnement essentiel” (Tradução Helena Mello).

${ }^{9}$ A tradução literal seria "não sei o que" mas, trata-se de uma expressão utilizada também em português que se refere a algo que não se identifica, algo indefinível (Tradução Helena Mello).

${ }^{10}$ Ce qui m’intéresse em définitive, c'est de voir comment um acteur à s'absenter em représentation. Pour être explicite, jê pense qu'on Ne peut pas interroger et investir cette notion de présence au théâtre sans l'opposer à son contraire: l'absence. Car, entre ces deux pôles, toutes sortes de degrés de présence opèrent en représentation, vis-à-vis de soi-même ou des autres, ou des deux à la fois. Il y a toute une gamme d'états de présence que l'interprète doit pouvoir explorer dans les textes de Samuel Beckett ou de Jon Fosse. Il existe des zones intermédiaires d'où parlent leurs personnages qui font entendre bien des fantômes dans leurs voix remplies de souvenirs, de rêves, de lapsus et d'inquiétudes. Cela nous ramène encore à Tadeusz Kantor qui prenait la marionnette ou la poupée de cire comme modèle du vivant pour l'acteur (Tradução Helena Mello).

${ }^{11}$ Em palestra proferida no III Seminário Internacional sobre Teatro, Dança e Performance, com o tema Poéticas Tecnológicas, de Salvador, em 05 de novembro de 2010. 
${ }^{12}$ Idem.

${ }^{13}$ A artista canadense Janet Cardiff (Ontário, 1957) graduou-se em 1980 na Queen's University (BFA) e em 1983 na University Alberta (MVA). Vem desenvolvendo um trabalho articulado entre sound art, vídeo e instalação desde os anos 1990, frequentemente, em colaboração com o seu parceiro, George Bures Miller (Vegreville, Canadá, 1960). Ganhou prêmio de notoriedade internacional por suas caminhadas de áudio em 1995.

${ }^{14}$ Esta montagem contou com a colaboração artística de Stéphanie Jasmin e foi uma coprodução entre o "UBU”, o "Musée d'art contemporain" de Montréal e o "Festival d’Avignon”. O elenco foi composto por Céline Bonnier e Paul Savoie.

15 Elles représentent quelque référent, comme tout signe, mais elles le présentent aussi, elles lui donnent une présence réelle, par une sorte de transsubstantiation. Mais cette présence reste singulière. Elle n'est plus celle, utopique, de la représentation classique, où le signe s'efface pour mieux représenter son référent, ni encore celle, tout aussi utopique, de la présentation moderne, où le référent se présente lui-même hors de toute signe. Elle est une présence marquée d'absence, une absence étrangement présente, une nouvelle aura - "l'unique apparition d'un lointain, si proche soit-il", comme la définissait Benjamin (Tradução Helena Mello).

${ }^{16}$ Em palestra proferida no III Seminário Internacional sobre Teatro, Dança e Performance, com o tema Poéticas Tecnológicas, de Salvador, em 05 de novembro de 2010.

${ }^{17}$ Car si le principe structurel du théâtre est bien la relation multiple, l'échange entre des êtres humains rassemblés, lorsque la technologie des images, simple ou sophistiquée, permet de transformer, de modifier cette relation, cette interaction, sans l'anesthésier, mais en la rendant plus consciente et/ou plus sensible, elle touche au coeur même du théâtre et, pour cela, doit être interrogée, comme doit l'être aussi le désintérêt obstiné de nombre d'artistes de théâtre pour les nouvelles (Tradução Helena Mello).

\section{Referências}

ASSELIN, Olivier. Le Fantôme et L'Autome. De la Reproductibilité Technique sur la Scène. Alternatives Théâtrales, Modernité de Maeterlinck/Denis Marleau, Bruxelles, n. 73-74, p. 24-29, 2002. Disponível em: <www.alternativestheatrales.be/catalogue/revue/73-74>. Acesso em: 02 out. 2010.

BARBA, Eugenio. A Canoa de Papel: tratado de antropologia teatral. Brasília: Teatro caleidoscópio, 2009.

DE MARINIS, Marco. Comprender el Teatro: lineamientos de una nueva teatrología. Editora Galerna: Buenos Aires, 1997.

DUSIGNE, Jean-François. L'Incandescence, la Fleur et le Garde-fou. In: FARCY, GérardDenis; PRÉDAL, René (Org.). Brûler les Planches, Crever l'Écran - la présence de l'acteur. Montpellier: L'entretemps éditions, 2001. P. 21-31.

FARCY, Gérard-Denis. Du Singulier au Pluriel. In: FARCY, Gérard-Denis; PRÉDAL, René (Org.). Brûler les Planches, Crever l'Écran - la présence de l'acteur. Montpellier: L'entretemps éditions, 2001. P. 13-20. 
FÉRAL, Josette. Encontros com Ariane Mnouchikine: erguendo um monumento ao efêmero. Tradução de Marcelo Gomes. São Paulo: Editora Senac, 2010.

PAVIS, Patrice. A Encenaçáo Contemporânea: origens, tendências, perspectivas. São Paulo: Perspectiva, 2010.

PICON-VALLIN, Béatrice. Les Écrans sur la Scène. Lausanne: L’age d’homme, 1998.

PROUST, Sophie. Denis Marleau - introduction et entretiens. Arles: Actes Sud-Papiers, 2010.

SILVA, Marta Isaacsson de Souza e. Desdobramentos do Ator e do Personagem pela Máscara Videográfica. Repertório Teatro \& Dança, Salvador, n. 14, p. 13-20, 2010.

Maíra Castilhos Coelho é atriz, mestra em Artes Cênicas pelo programa de pósgraduação da Universidade Federal do Rio Grande do Sul. Bacharel em Artes Cênicas pela Universidade Federal do Rio Grande do Sul (2003), com formação em cinema pelo Studio Fátima Toledo (2004).

E-mail: mcastilhos@gmail.com

Recebido em 26 de junho de 2012 Aprovado em 18 de abril de 2013 